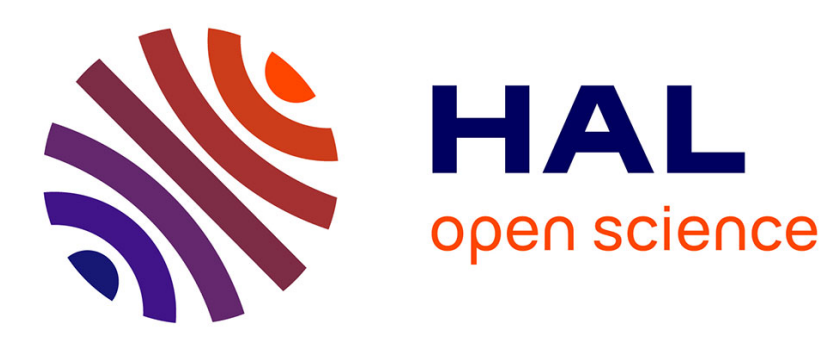

\title{
Damage mechanics of interfacial media: Basic aspects, identification and application to delamination
}

\author{
Olivier Allix, Pierre Ladevèze
}

\section{To cite this version:}

Olivier Allix, Pierre Ladevèze. Damage mechanics of interfacial media: Basic aspects, identification and application to delamination. Studies in Applied Mechanics, 1996, 44, pp.167-188. 10.1016/S09225382(96)80010-9 . hal-01759147

\section{HAL Id: hal-01759147 \\ https://hal.science/hal-01759147}

Submitted on 7 Jan 2020

HAL is a multi-disciplinary open access archive for the deposit and dissemination of scientific research documents, whether they are published or not. The documents may come from teaching and research institutions in France or abroad, or from public or private research centers.
L'archive ouverte pluridisciplinaire HAL, est destinée au dépôt et à la diffusion de documents scientifiques de niveau recherche, publiés ou non, émanant des établissements d'enseignement et de recherche français ou étrangers, des laboratoires publics ou privés. 
Damage Mechanics of interfacial media: basic aspects, identification and application to delamination

O.Allixa\&b and P. Ladevèzea

a Laboratoire de Mécanique et Technologie, E.N.S. de Cachan/C.N.R.S./ Université Paris

6, 61, avenue du Président Wilson, 94230 Cachan - France

b Université d' Evry-Val-d' Essonne/ IUT GMP

2 cours Monségnieur Roméro, 91000 Evry Cédex -France

The aim of this paper is to develop a bridge between damage mechanics and delamination. For this a previously defined Damage Meso-Modeling of composite laminates is used. The interlaminar interfacial deterioration as well as the main inner layer damage mechanisms are included. However, attention is focused herein on the modeling of the interlaminar connection as an elastic interfacial and damageable medium. The connection with Fracture Mechanics and the identification on an interface damage model devoted to the delamination prediction is also addressed. Examples of comparison between simulation and experiments are included.

\section{INTRODUCTION}

Our aim is to build a bridge between damage mechanics and delamination by including all the damage mechanisms in delamination analysis. Delamination often appears as the result of interactions between different damage mechanisms, such as fiber-breaking, transverse microcracking and debonding of the adjacent layers themselves [1-4]. Thus a damage mesomodeling, proposed in [5-6] and developed in [7-9], which includes both inner layer damage mechanisms and interfacial ones is used

At the meso-level, the laminate is described as a stacking sequence of inelastic and damageable homogeneous layers throughout the thickness and of damageable interlaminar interfaces. The single-layer model being identified, the aim is to determine the properties of any structures regarding delamination by knowing only a few characteristics of the interface. The word interface denotes here a physical yet two-dimensional medium. At the present applications only concern static loading without buckling.

The single layer model and its identification, including damage (such as fiber-breaking, transverse cracking and deterioration of the fiber-matrix bond ) and inelasticity, were 
previously developed [5],[10]. The interlaminar interface is a two-dimensional entity which ensures traction and displacement transfer from one ply to another. Its mechanical behaviour depends on the angles between the fibers of the two adjacent layers.

Here we pay special attention to the basic aspects of the interlaminar interface model: definition, debonding and sliding effects modeling, qualitative connection with "micro information" and questions concerming identification. Therefore results given in [8], [1114] are detailed. Moreover last simulations are presented. For identification purposes the existing links and differences between Damage Mechanics of composites and Fracture Mechanics are analyzed. In particular the interest of using a Damage Mechanics approach for initiation prediction and for the interpretation of standard Fracture Mechanics tests, in connection with experiments [15-18], is discussed.

These comparisons require numerical tools in order to simulate, up to failure, the behaviour of any stacking sequence. The use of classical damage modeling for the simulation of failure has led to many theoretical and numerical difficulties which are well-understood at the present time [19]. The solution which is used for laminates, and more generally for composites, is based on the meso-model concept [6]. The physical meaning of this concept is that the state of damage is uniform in each meso-constituent. For example, the damage state is uniform throughout the thickness of each single layer. To be able to perform a complete analysis of the delamination process in all cases, damage models with delay effects are introduced for the inplane direction. These models should be, at least theoretically, combined with a dynamic analysis of the structure [8].

\section{MESO-MODELING CONCEPT FOR COMPOSITE LAMINATES}

Let us recall that delamination often appears as an interaction between fiber-breaking, transverse micro-cracking and debonding of adjacent layers itself. In order to take these mechanisms into account, the first issue is the scale at which they are modeled. For laminates three different scales may easily be defined, the micro scale of individual fiber, the meso scale associated with the thickness of the elementary ply and the macro scale which is the structural one. Due to the low thickness ( $1 / 10$ of $\mathrm{mm}$ ) of the elementary ply and the kinematics of the deterioration inside of the ply ( fiber oriented ) it is possible and of interest to derive a material model at the mesoscale. The one proposed in [5-6] is defined by two meso-constituents:

- a single layer

- an interface which is a mechanical surface connecting two adjacent layers and depending on the relative orientation of their fibers. 


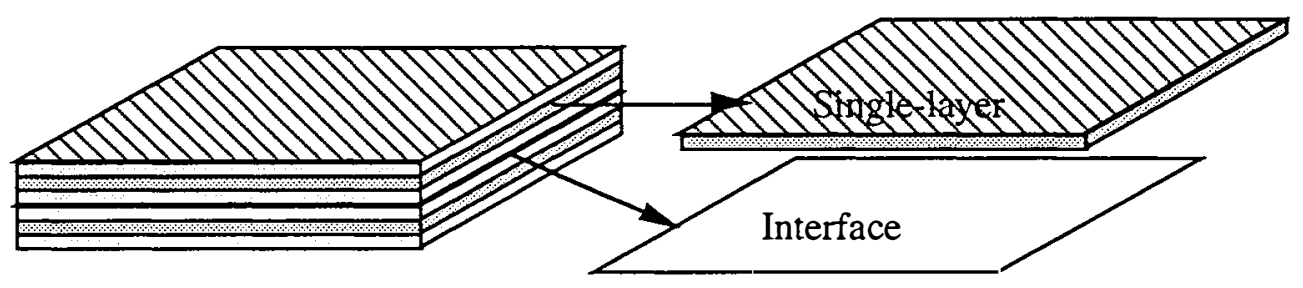

Figure 1. Laminate modeling

A mesomodeling is then defined by adding another property: a uniform damage state is prescribed throughout the thickness of the elementary ply. This point plays a major role when trying to simulate a crack with a damage model. With this property, Damage Mechanics "contains" Fracture Mechanics, i. e. it gives a correct value of the critical energy release rate. Let us recall that, in order to be able to perform a complete analysis of the delamination process in all cases, damage models with delay effects are introduced for the in-plane direction. These model should be, at least theoretically, combined with a dynamic analysis of the structure [8].

One limitation of the proposed meso-modeling is that the fracture of the material is described by means of only two types of macrocracks:

- delamination cracks within the interfaces

- cracks, orthogonal to the laminate, with each cracked layer being completely cracked in its thickness.

Let us recall that the single layer model and its identification, including damage such as liber-breaking and transverse micro-cracking as well as inelastic effects were previously developed in [5],[10]. In paragraph 3 the interface model is detailed.

\section{INTERFACE MODELING}

\subsection{Elastic modeling of the interface}

The scheme which leads to the definition of the interface is classical for isotropic bimaterials. The interlaminar connection is considered as a ply of matrix (denoted by $\Omega$ ) whose thickness (denoted by e), is small compared to the in-plane dimension whose characteristic length is denoted by $\mathrm{L}$ (figure 2.). 


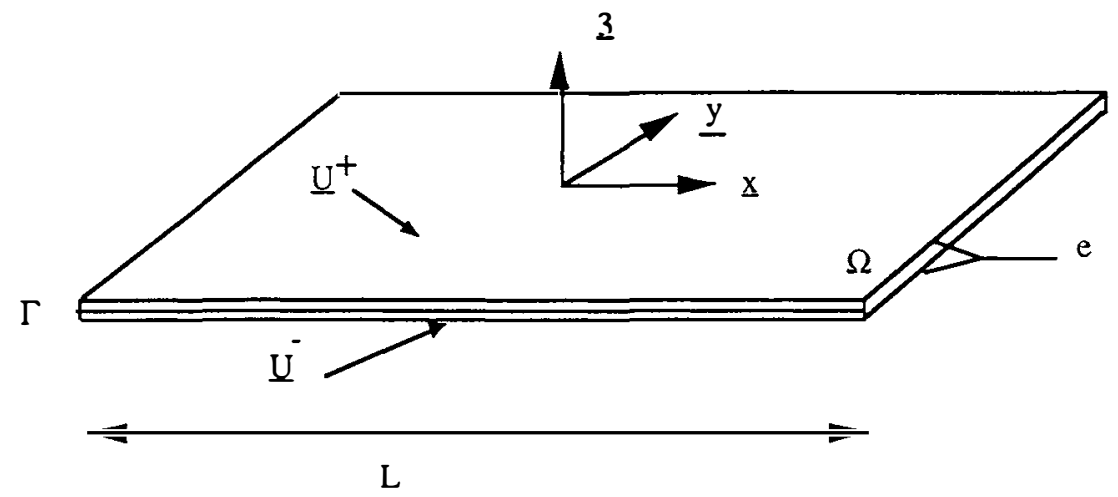

Figure 2. Interface Scheme

Therefore, the wavelength of the displacement in normal direction $\underline{3}$ is of the order of magnitude of $e$, while the wavelength of the displacement fields in the plane $(x, y)$ is of the order of $L$. The strain fields may therefore be asymptotically expanded under the form:

$\varepsilon(\underline{U})=\varepsilon_{0}+\frac{e}{L} \varepsilon_{1}+\ldots$

where $\underline{U}$ is the displacement field. Let us denote ${ }^{t}$ the transposition, then:

$\varepsilon_{0} \approx\left(3 \cdot{ }^{\mathrm{t}} \frac{\partial \underline{\mathrm{U}}}{\partial \mathrm{z}}\right)_{\text {sym }}$ with: $\frac{\partial \underline{\mathrm{U}}}{\partial \mathrm{z}} \approx \frac{[\underline{\mathrm{U}}]}{\mathrm{e}}$

where: $[\underline{U}]=\underline{U}^{+}-\underline{U}^{-}$is the difference of displacements between the upper and lower surfaces of $\Omega$. Thus, at the first order, the strain energy of $\Omega$ is:

$\mathrm{E}_{\mathrm{d}}=\frac{1}{2} \int_{\Omega} \operatorname{Tr}\left[\mathrm{K} \varepsilon_{0} \varepsilon_{0}\right] \mathrm{d} \Omega=\frac{1}{2} \mathrm{e} \int_{\Gamma} \frac{[\mathrm{U}]^{\mathrm{T}}}{\mathrm{e}} \mathrm{H} \frac{[\mathrm{U}]}{\mathrm{e}} \mathrm{d} \Gamma$

where $\Gamma$ is the area of the mid-plane of $\Omega$, and $H$ is a $(3,3)$ symmetric matrix. Let us denote by $(1,2)$ the bisectors of the fiber directions. They are necessarily "orthotropic" directions of the interface, since a $\left[\theta_{1}, \theta_{2}\right]$ interface is equivalent to a $\left[\theta_{2}, \theta_{1}\right]$ interface. Then in the $((1, \underline{2}, \underline{3})$ axis, the elastic strain energy of the interface may be written as follows:

$\mathrm{E}_{\mathrm{d}}=\frac{1}{2} \int_{\Gamma}\left[\mathrm{k}_{\mathrm{o}}\left[\mathrm{U}_{3}\right]^{2}+\mathrm{k}_{\mathrm{o}}^{1}\left[\mathrm{U}_{1}\right]^{2}+\mathrm{k}_{\mathrm{o}}^{2}\left[\mathrm{U}_{2}\right]^{2} \mathrm{~d} \Gamma=\frac{1}{2} \int_{\Gamma}\left[\frac{\sigma_{33}^{2}}{\mathrm{k}_{\mathrm{o}}}+\frac{\sigma_{13}^{2}}{\mathrm{k}_{\mathrm{o}}^{1}}+\frac{\sigma_{23}^{2}}{\mathrm{k}_{\mathrm{o}}^{2}}\right] \mathrm{d} \Gamma\right.$

where $k_{0}, k_{0}^{1}, k_{0}^{2}$ are elastic characteristics of the interface. 
The interlaminar connection is thus modeled as a two-dimensional entity which ensures stress and displacement transfers from one ply to another.

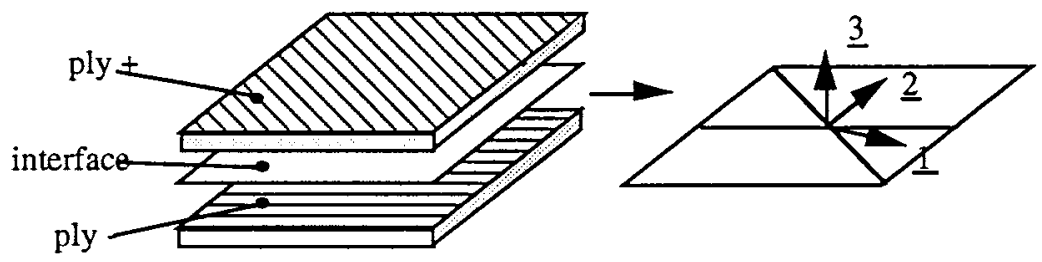

Figure 3. "Orthotropic" directions of the interface

Let us remark that in [20] the mechanical effect of the change in the fiber orientation of two adjacent plies is interpreted as a "wall effect". This leads to an equivalent thickness e of the interface equal to two times the diameter of one fiber. The same interpretation, associated with relation (1), leads to stiffness values $k_{0}, k_{0}^{1}$ and $k_{0}^{2}$ of the same order of magnitude as $\frac{E_{m}}{e}$, where $E_{m}$ is an average transverse characteristic modulus of the matrix and of the fiber. Therefore, e being small, $\mathrm{k}_{0}, \mathrm{k}_{\mathrm{O}}^{1}, \mathrm{k}_{\mathrm{O}}^{2}$ have very high values and the interlaminar connection behaves, in elasticity, as a perfect bond: it ensures displacements and traction continuities. In the non-linear case, it ensures traction continuity only.

\subsection{Interfacial damage indicators}

The ideas and framework which govern the interface damage modeling are similar to those which are used for deriving the layer damage modeling [5],[10]. The effect of the deterioration of the interlaminar connection on its mechanical behaviour is taken into account by means of damage internal variables. The different damageable behaviour in "tension" and in "compression" are distinguished by splitting the strain energy into "tension-energy " and "compression-energy". More precisely we use the following expression, proposed in [5], of the energy per unit area:

$E_{D}=\frac{1}{2}\left[\frac{\left\langle-\sigma_{33}\right\rangle^{2}}{k^{0}}+\frac{\left\langle\sigma_{33}\right\rangle^{2}}{k^{0}(1-d)}+\frac{\sigma_{32}^{2}}{k_{2}^{0}\left(1-d_{2}\right)}+\frac{\sigma_{31}^{2}}{k_{1}^{0}\left(1-d_{1}\right)}\right]$

thus three internal damage indicators, associated with the three Fracture Mechanics modes are introduced. 
These evolution laws must satisfy the Clausius-Duheim inequality. Classically the damage energy release rates, associated with the dissipated energy $\omega$, by damage and by unit area, are introduced:

$Y_{d}=\frac{1}{2} \frac{<\sigma_{33}>_{t}^{2}}{k^{0}(1-d)^{2}} ; Y_{d_{1}}=\frac{1}{2} \frac{\sigma_{31}^{2}}{k_{1}^{0}\left(1-d_{1}\right)^{2}} ; Y_{d_{2}}=\frac{1}{2} \frac{\sigma_{32}^{2}}{k_{2}^{0}\left(1-d_{2}\right)^{2}}$

with:

$\omega=Y_{d} \dot{d}+Y_{d_{1}} \dot{d}_{1}+Y_{d} \dot{d}_{2} \quad(\omega \geq 0)$

In what follows two type of damage evolution laws are described. The first type is based on the assumption that the evolution of the different damage indicators is strongly coupled and driven by a unique equivalent damage energy release rate. This type could be called "isotropic", even if the behaviour is the different mode are different. This is the type of model which has been used so far. The different versions mainly differ in the choice of the coupling.

The second class is inspired by our knowledge of the damage behaviour of the single layer. The in-plane behaviour of the layer is nearly brittle in normal tension and "ductile" in shear. Thus it can be assumed that the hehaviour in mode I is brittle and that the behaviour in modes II and III is "ductile".

\section{Isotropic damage evolution law}

The following model, proposed in [14],[21], considers that the damage evolution is governed by means of an equivalent damage energy release rate of the following form:

$Y(t)=\sup _{\tau \leq t}\left[\left(Y_{d^{+}}^{\alpha}+\left(\gamma_{1} Y_{d_{1}}\right)^{\alpha}+\left(\gamma_{2} Y_{d_{2}}\right)^{\alpha}\right)_{\mid \tau}^{1 / \alpha}\right]$

this means that (i) the evolution of the damage indicators are assumed to be coupled (as for single layers) (ii) the damage evolution depends (mainly) on the maximal value of the equivalent damage energy release rate. $\gamma_{1}, \gamma_{2}$ and $\alpha$ are material parameters. In terms of delamination modes, the first term is associated with the first opening mode, and the two others are associated with the second and third modes.

Compared to other damage evolution laws, used for example in [5-9], an enhanced coupling model, associated with the parameter $\alpha$ is proposed. The interest is to describe Fracture Mechanics failure loci which are quite general ( see paragraph 4.2).

A damage evolution law is then defined by the choice of a material funcrion $\omega$, such that : 
$\mathrm{d}=\mathrm{d}_{1}=\mathrm{d}_{2}=\omega(\mathrm{Y})$ if $\mathrm{d}<1 ; \mathrm{d}=\mathrm{d}_{1}=\mathrm{d}_{2}=1$ otherwise

a simple case, used for application, is:

$\omega(Y)=\left[\frac{n}{n+1} \frac{\left.<Y_{-}-Y_{0}\right\rangle_{+}}{Y_{c}-Y_{0}}\right]^{n}$

where a critical value $Y_{c}$ and a threshold value $Y_{0}$ are introduced. The high values of $n$ case corresponds to brittle interface.

To summarize, the damage evolution law is defined by means of six intrinsic material parameters $Y_{c}, Y_{0}, \gamma_{1}, \gamma_{2}, \alpha$ and $n$. It is shown in paragraph 4 that $Y_{c}, \gamma_{1}, \gamma_{2}$ and $\alpha$. are related to the critical energy release rates. The threshold $\mathrm{Y}_{\mathrm{O}}$ is introduced here in order to enlarge the possibility to describe both the creation of a delamination crack and its propagation. As regards the creation of a new delamination crack the significant parameters are $\mathrm{Y}_{\mathrm{o}}, \mathrm{n}$ and $\alpha$.

\section{Anisotropic damage evolution law}

Here the evolution of $d$ is assumed to be governed only by $Y_{d}$ and the evolution of $d_{1}$ and $d_{2}$ by a common shear damage energy release rate $\underline{Y}_{12}$ with:

$\underline{Y}_{d}(t)=\left.\sup \right|_{\tau \leq t}\left[\left.Y_{d}\right|_{\tau}\right]$

$\left.\underline{Y}_{12}(t)=\left.\sup \right|_{\tau \leq l}\left[\left(\gamma_{1} Y_{d_{1}}\right)^{\alpha}+\left(\gamma_{2} Y_{d_{2}}\right)^{\alpha}\right)_{\tau}^{1 / \alpha}\right]$

two damage evolution laws are then defined:

$\mathrm{d}=0$ if $\underline{Y}_{\mathrm{d}} \leq \mathrm{Y}_{\mathrm{C}}^{\prime}$ and $\mathrm{d}_{1}=\mathrm{d}_{2}<1 ; \quad \mathrm{d}=1$ otherwise

$d_{1}=d_{2}=\omega\left(Y_{12}\right)=\left[\frac{n}{n+1} \frac{<\underline{Y}_{12}-Y_{0}{ }}{Y_{c^{-}} Y_{0}}\right]^{n}$ if $d_{1}=d_{2}<1$ and $d<1 ; \quad d_{1}=d_{2}=1$ otherwise

Consequently the damage evolution laws in mode I and modes II and III are decoupled. These damage evolutions are always supposed to depend on the maximal value of the driving damage energy release rate.

\subsection{Inelas tic effects coupled with damage}

Although their identification has not yet been investigated, in-plane inelastic effects, due to friction, certainly exist. Moreover, one may assume that the level of interfacial damage modifies the interfacial inelastic properties, as in the layer case [10]. Following [8], these 
inelastic aspects can be taken into account by introducing an inelastic part of the displacement discontinuities $\left[U_{1}\right]^{p}$, $\left[U_{2}\right]^{p}$. Damage and inelasticity coupling is then modeled by defining the following effective quantities:

$$
\begin{aligned}
& {\left[\tilde{\mathrm{U}}_{1}\right]^{\mathrm{p}}=\left[\dot{\mathrm{U}}_{1}\right]^{\mathrm{p}}\left(1-\mathrm{d}_{1}\right) ; \quad\left[\tilde{\mathrm{U}}_{2}\right]^{\mathrm{p}}=\left[\dot{\mathrm{U}}_{2}\right]^{\mathrm{p}}\left(1-\mathrm{d}_{2}\right)} \\
& \tilde{\sigma}_{1}=\frac{\sigma_{13}}{1-\mathrm{d}_{1}} \quad ; \quad \tilde{\sigma}_{2}=\frac{\sigma_{23}}{1-d_{2}} \quad ; \quad \tilde{\sigma}_{3}=\frac{\left\langle\sigma_{33}\right\rangle}{(1-\mathrm{d})}+\left\langle\sigma_{33}\right\rangle .
\end{aligned}
$$

Considering the previous relations it appears that no friction is assumed in the normal direction. A plasticity like-model which makes use of these effective quantities is then defined:

$\mathrm{f}\left(\tilde{\sigma_{1}}, \tilde{\sigma_{2}}, \tilde{\sigma_{3}}, \mathrm{R}\right)=\sqrt{\mathrm{a}_{1}^{2}{\tilde{\sigma_{1}}}^{2}+\mathrm{a}_{2}^{2} \tilde{\sigma_{2}}}-\tilde{\sigma_{3}}-\mathrm{R}(\mathrm{p}) \leq 0$

$f$ defines the elastic domain, $a_{1}$ and $a_{2}$ are two material parameters and $R(p)$ is the effective hardening function. A Coulomb like-effect is taken into account by means of the normal effective stress $\tilde{\sigma}_{3}$. Within the framework of standard materials one obtains:

$$
\left[\tilde{U}_{1}\right]^{\mathrm{p}}=\dot{\mathrm{p}} \frac{\mathrm{a}_{1}^{2} \tilde{\sigma_{1}}}{\sqrt{\mathrm{a}_{1}^{2}{\tilde{\sigma_{1}}}^{2}+\mathrm{a}_{2}^{2} \tilde{\sigma_{2}}}} \quad ; \quad\left[\tilde{\mathrm{U}}_{2}\right]^{\mathrm{p}}=\dot{\mathrm{p}} \frac{\mathrm{a}_{2}^{2} \tilde{\sigma_{2}}}{\sqrt{\mathrm{a}_{1}^{2} \tilde{\sigma}_{1}^{2}+\mathrm{a}_{2}^{2} \tilde{\sigma_{2}}}} \quad \text { and } \dot{\mathrm{p}} \geq 0
$$

where:

$$
\left.\mathrm{p}=\int_{0}^{\mathrm{t}}\left(\frac{\left[\tilde{\mathrm{U}}_{1}\right]^{\mathrm{p}}}{\mathrm{a}_{1}^{2}}\right)^{2}+\frac{\left[\tilde{\mathrm{U}}_{2}\right]^{\mathrm{p} 2}}{\mathrm{a}_{2}^{2}}\right) \mathrm{dt}
$$

Due to the difficulty of the identification we propose, in a first approach, to chose:

$$
\begin{aligned}
& -R(p)=R_{0} \\
& -a_{1}=a_{2}=1 .
\end{aligned}
$$

\subsection{Extension: damage model with delay effects}

In order to get, in all cases, a consistent model for the description of the rupture a variant of the previous damage model, introducing delay effects [6] is introduced. It as to be combined, in the principle, with a dynamical analysis of the structure. This variant ensures the physical following properties:

- a variation of the driving force $Y$ does not lead to an instantaneous variation of $d$

- the damage rate is bounded

More precisely the rate of the damage indicator is defined by: 
$\dot{d}=\frac{1}{T_{c}}\left[1-\exp \left(-a<\omega(Y)-d>_{+}\right)\right]$if $d<1 d=1$ otherwise

\section{Remark:}

In many practical situations, a model without delay effect is sufficient. This is the case, in particular, for $2 \mathrm{D}$ problems where the crack is described by a line.

\section{DAMAGE INTERFACE MODEL IDENTIFICATION: A FIRST APPROACH}

\section{1 Basic remarks}

In delamination studies, the analysis of the creation of a crack is generally separated from that of its propagation. In comparison, the use of a damage interface model allows for taking into account the initiation and propagation within the same framework [9]. Nevertheless the identification of all the interfacial characteristics leads to numerous difficulties.

A first difficulty is that the interface model identification cannot be achieved studying large delamination cracks only. Such situations, encountered in classical Fracture Mechanics tests are used to determine (at least theoretically) the critical energetic characteristics of the interfacial damage model, but not the type of damage evolution law.

For this, one has to consider the creation of a delamination crack and the beginning of its propagation. In such situations, a complex three-dimensional state of stress occurs, and this does not permits a simple and direct identification. Furthermore, in such cases, different damage mechanisms most often interact.

A first strategy to determine the interfacial characteristics is thus to use classical Fracture Mechanics tests to determine the critical energetic characteristics of the interfacial damage model. The other characteristics must be determined, if possible, by comparison between experiments and tests in situations involving the creation of a delamination crack.

\subsection{Possibilities of using Fracture Mechanics tests for the identification of the damage interface model}

Linear Elastic Fracture Mechanics (LEFM) is the most commonly used approach for dealing with the propagation of delamination. Thus, any modeling of delamination propagation has to be compared to LEFM in that situation. Furthermore, different tests are used in order to identify the Critical Energy Release Rate both in pure mode [15], [18] and in mixed mode [15]. So a clear comparison with LEFM allows using these tests for the identification of the delamination model. Below we first exhibit the link between LEFM and Damage Mechanics of the Interface both in pure mode I in continuity of [11] and [13] and in mixed mode in continuity of [14] and [21].

In fact, even for the propagation of delamination, LEFM does not provide an explanation or allow us to predict experimental results obtained in quite common situations. An example 
is the situation of inner layer dissipative phenomena. Another example is the situation of fiber-bridging leading to R-curve-like phenomena. The possibility of predicting this last situation by means of an interfacial damage model is discussed in [21].

\section{Comparison between Linear Elastic Fracture Mechanics and Damage Model of the Interface}

Delamination is a dissipative phenomenon. A simple way to compare Damage Mechanics with LEFM is to compare the mechanical dissipation given by the two approaches. For LEFM, it is well-known that the total dissipated power, in the case of a single crack whose area is $\mathrm{S}$, is:

$\mathrm{P}_{\mathrm{d}}=\mathrm{G} \dot{\mathrm{S}}$

Within the framework of Damage Mechanics of Interface and assuming that the only dissipative process occurs on one interface $\Gamma$, the total dissipated power is:

$\mathrm{P}_{\mathrm{d}}=\int_{\Gamma} \mathrm{Y}_{\mathrm{d}_{\mathrm{i}}} \dot{\mathrm{d}}_{\mathrm{i}} \mathrm{d} \Gamma=\int_{\Gamma}\left(\sum_{\mathrm{i}=1}^{\mathrm{i}=3} \mathrm{Y}_{\mathrm{d}_{\mathrm{i}}}\right) \dot{\mathrm{d}} \mathrm{d} \Gamma$

In many classical Fracture Mechanics tests, the crack is assumed to be rectilinear and is parametered by a scalar "a" such that: $\dot{S}=b$ a where $b$ is the width of the specimen. Under this assumption the integration of relations (4) and (5) over a time $\Delta t$ during which the crack extends by a length of $\Delta$ a leads to:

$\int_{\Delta t} P_{d} d t=G_{c}(a) b \Delta a$

Let us define the location of the crack by $d=1$. In order to explicitly integrate the equation (4), a steady-state situation is assumed. This means that the process zone (defined as the area where $\mathrm{d}$ is between 0 and 1 ) is translated from $\Delta \mathrm{a}$ over time $\Delta \mathrm{T}$ (Fig . 4).

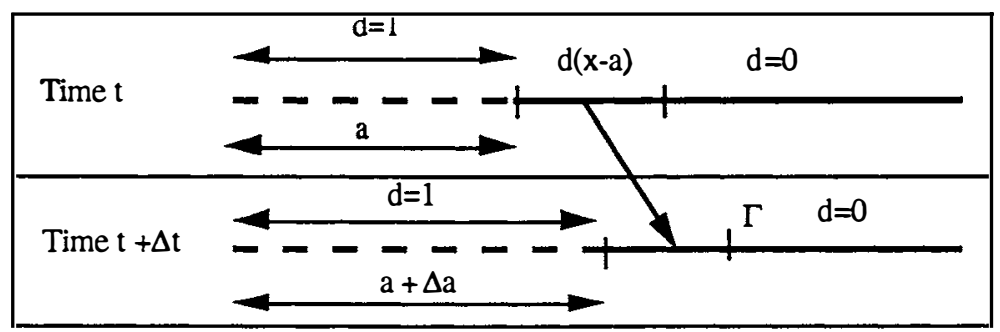

Figure. 4 Diagram of a steady-state delamination process

In this case one obtains: 
$\int_{\Delta t} P_{d} d t=\left(\int_{d=0}^{d=1}\left(\sum_{i=1}^{i=3} Y_{d_{i}}\right) \delta d\right) b \Delta a$

In such a steady state process $G_{c}(a)$ reaches its stabilised value at the propagation denoted by $G_{c}^{p}$. This leads to:

$G_{c}^{p}=\int_{d=0}^{d=1}\left(\sum_{i=1}^{i=3} Y_{d_{i}}\right) \delta d$

and using relation (5) the energy release rate is split into three terms:

$G_{I}=\int_{d=0}^{d=1} Y_{d} \delta d ; G_{I I}=\int_{d=0}^{d=1} Y_{d_{1}} \delta d ; G_{I I I}=\int_{d=0}^{d=1} Y_{d_{2}} \delta d$

A mixed mode situation is defined by the mode coupling ratios $\mathrm{c}_{\mathrm{II}}$ and $\mathrm{c}_{\mathrm{III}}$, such that:

$\underline{Y}_{d_{1}}=c_{I I} \underline{Y}_{d}$ and $\underline{Y}_{d_{2}}=c_{I I I} \underline{Y}_{d}$

The previous considerations do not depend on the damage evolution law. To go further the type of damage evolution law must be specified. An example of an isotropic damage evolution law is treated below.

In that case relation (9) becomes:

$\mathrm{G}_{\mathrm{II}}=\mathrm{c}_{\mathrm{II}} \mathrm{G}_{\mathrm{I}}$ and $\mathrm{G}_{\mathrm{III}}=\mathrm{c}_{\mathrm{III}} \mathrm{G}_{\mathrm{I}}$

and, making use of relations (3), (7) and (9'), one obtains:

$$
\int_{d=0}^{d=1}\left(\sum_{i=1}^{i=3} Y_{d_{i}}\right) \delta d=\frac{\left(1+c_{I I}+c_{I I I}\right) Y_{c}}{\left(1+\left(\gamma_{1} c_{I I}\right)^{\alpha}+\left(\gamma_{2} c_{I I I}\right)^{\alpha}\right)^{1 / \alpha}}=G_{c}^{p}
$$

and thus for pure mode situations:

$G_{c I}^{p}=Y_{c} ; G_{c I I}^{p}=\frac{Y_{c}}{\gamma_{1}} ; G_{c I I I}^{p}=\frac{Y_{c}}{\gamma_{2}}$

Substituting $\gamma_{1}$ and $\gamma_{2}$ in relation (12) and using (9) into account, one obtains:

$$
\left(\frac{G_{1}}{G_{c l}^{p}}\right)^{\alpha}+\left(\frac{G_{\mathrm{II}}}{G_{c I I}^{p}}\right)^{\alpha}+\left(\frac{G_{\mathrm{III}}}{G_{c m}^{p}}\right)^{\alpha}=1
$$


Relations (12) and (13) show that the only significant parameters of the Damage Evolution law are, $Y_{c}, \gamma_{1}, \gamma_{2}$ and $\alpha$. From equation (19) it appears that $\alpha$ governs the shape of the failure locus in mixed-mode.

There exist few experimental results concerning mixed-mode crack propagation. In [15], experimental results on a poly(ether sulphone)-carbon fiber composite are given. They have been obtained using an AELS specimen. They were used here for the identification of $\alpha$ by means of relation (13). We obtained $\alpha=.72$. The result of the identification is presented in figure 5 .

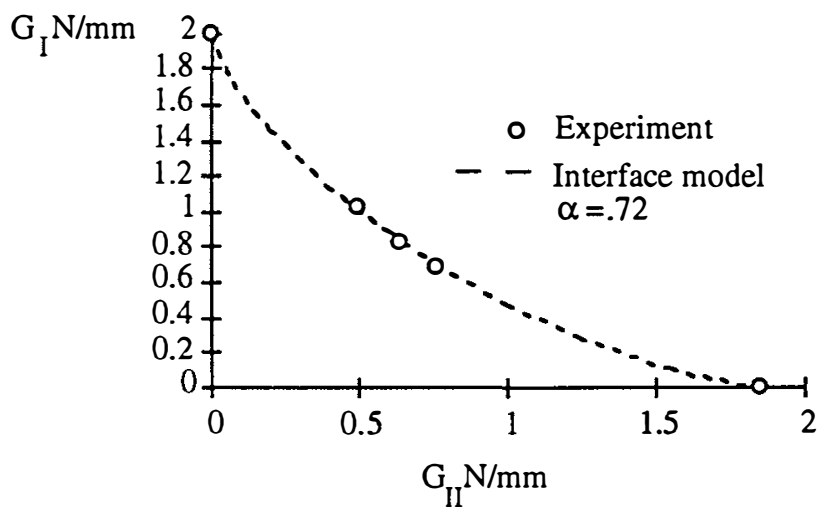

Figure 5

\subsection{Example of "pure mode I" testing: interest and difficulties.}

Regarding the identification of the damage interface model, the interest of classical F.M tests relies on the possibility to identify the local critical energy release rate. Such tests are usually analyzed by means of LEFM. Nevertheless, in the case of carbon-epoxy laminates, the main assumptions of LEFM are not always satisfied even in the simple case of a DCB specimen. This is true, in particular in the case of:

- non-unidirectional stacking sequence

- $\mathrm{R}$ curve like phenomena

In the first situation inner layer damage mechanisms may be activated leading to an apparent energy release rate different from the local interfacial one. In that case, a non-linear damage analysis should be performed.

$\mathrm{R}$ curve-like phenomena appear when the size of the non linear domain is comparable to that of the specimen. This happens, for example, in the problem of fiber-bridging. In that case also it appears to be more interesting to use Damage Mechanics rather than LEFM. 


\section{Influence of inner-layer damage mechanisms}

An example, coming from [13], which makes use of the experimental results of [18] is presented. Its interest is firstly to show the intrinsic character of the critical value $Y_{c}$, and secondly to emphasize the influence of the inner damage mechanisms on the apparent or global energy release rate. Using the apparent energy release rate would, in that case, lead to erroneous values of $Y_{c}$.

Two types of carbon-epoxy T300-vicotex M10 laminates have been tested in pure mode I by means of a D.C.B. specimen. The first one is a uni-directional (0\% 09 type, the second one a $\left[\left(90_{2} / 09\right)_{2} / 90_{2}\right] \mathrm{s}$ with the two layers adjacent to the delamination plane oriented at $90^{\circ}$ $\left(90990^{\circ}\right.$ case). The two specimens have 24 layers per arm.

In what follow a D.C.B. specimen is modeled as two homogeneous elastic layers connected by a damageable interface. A plane strain state is assumed in the width direction so that each arm may be modeled as a beam. The numerical scheme [13] makes use of Finite Element Computation associated with a Riks-type algorithm to be able to deal with unstable situations. The experimental results yield a value of $\mathrm{G}_{\mathrm{cl}}=\mathrm{Y}_{\mathrm{c}}=.45 \mathrm{~N} / \mathrm{mm}$, using this value leads to a satisfactory comparison between experimental and numerical results for the entire test. In [21], the same type of comparisons are given in mixed-mode situations.

Let us consider the $\left(90 \% 909\right.$ case. The experimental results yield a value of $\mathrm{G}_{\mathrm{cI}}\left(\mathrm{G}_{\mathrm{cI}}=\right.$ $1.05 \mathrm{~N} / \mathrm{mm})$, which is quite different from that obtained in the $\left(0 \% 09\right.$ case $\left(\mathrm{G}_{\mathrm{cI}}=\right.$ $.45 \mathrm{~N} / \mathrm{mm}$ ). This fact seems to conflict with the proposed scheme for the interface dependence on fiber direction. In fact, the angle between fiber directions of adjacent layers in the $\left(90 \% 909\right.$ case is equal to $0^{\circ}$ as in the $(0 \% 09$ case. Consequently, in the proposed model, the properties of the loaded interfaces are the same. Thus, it seems logical to use the value of $G_{c I}$ obtained in the $\left(0 \% 09\right.$ case $\left(G_{c I}=.45 \mathrm{~N} / \mathrm{mm}\right)$ even when dealing with the (909909) case.

In order to clarify this point, two computations have been performed. The first one uses an interface whose behaviour was identified with the $\left(0 \% 09\right.$ test (i.e. $\mathrm{G}_{\mathrm{CI}}=.45 \mathrm{~N} / \mathrm{mm}$ ), and the second one uses an interface identified with the $\left(90 \% 909\right.$ test (i.e. $\mathrm{G}_{\mathrm{cl}}=1.05 \mathrm{~N} / \mathrm{mm}$ ).

Figure 6 highlights the comparison between the numerical analyses conducted with the two different interfaces and the experimental data. It appears that the case of $G_{\mathrm{cl}}=.45 \mathrm{~N} / \mathrm{mm}$ gives a much better description of the experimental results than the other case.

This shows that the characteristics of the interface are intrinsic. One possible explanation of this fact is that the experimental value of $\mathrm{G}_{\mathrm{CI}}$ in the (90)/909 case includes the dissipative phenomena inside the $90^{\circ}$ layers (micro-cracking parallel to fiber direction). The values obtained are greater than those obtained in the $0 \% 0^{\circ}$ case. In this last case the dissipative phenomena inside the layers are negligible and thus $G_{\mathrm{CI}}$ may be attributed entirely to the delamination process. In fact, by introducing the dissipation inside the layer, one would 
obtain:

$G_{c}^{p}=\int_{d=0}^{d=1}\left(\sum_{i=1}^{i=3} Y_{d i}\right) \delta d \leq\left(G_{c}^{p}\right)_{a p p}=\frac{1}{2 b} P_{c}^{2} \frac{d C}{d a}=G_{c}^{p}+\frac{1}{b \Delta a} \int_{\Delta t} P_{d}^{1} d t$

where $\left(G_{c}^{p}\right)_{\text {app }}$ is the apparent critical energy release rate obtained by means of the compliance formulae (denoted here by $\mathrm{C}$ ), $\mathrm{P}_{\mathrm{d}}^{\mathrm{l}}$ is the total dissipated power inside the layer. In this case, the last term is thus equal to $.6 \mathrm{~N} / \mathrm{mm}$.

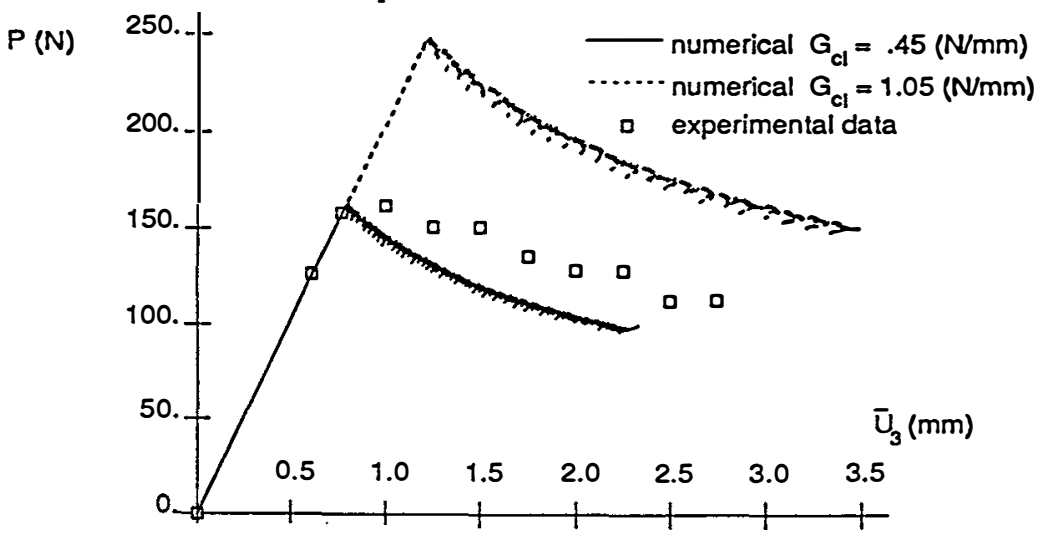

Figure. 6 comparison between experimental and numerical results in the $90 \% 90^{\circ}$ case for the two means of identification

This should be confirmed by a complete non-linear analysis including the damage and inelastic phenomena which occur due to transverse cracking.

From the above comparisons, one can state that, in a steady-state of propagation, the fracture energy $G_{C I}$ can be used to identify the interface model provided the dissipative phenomena occurring in the specimen are mainly associated with delamination crack propagation.

\section{R-curve phenomena: example of fiber-bridging}

The existence of fiber-bridging gives rise to R-curve like phenomenon. This type of phenomenon has long been the subject of intensive research [22-24]. The main difference, which occurs, for example in the case of fiber-bridging, is that the size of the equivalent process zone is very large. In [25], one can find a "large scale model" which is, in fact, a damage model. In [26], it is proposed to use an interface damage model (of the same type as the one presented in this paper) associated with a Griffith criterion at the tip of the fiberbridge. 
Damage Mechanics offers different possibilities for modeling and predicting $\mathrm{R}$-curve-like phenomenon, some of them are discussed herein.

The first possibility is based on the fact that $\mathrm{R}$-curve-like phenomena occur in non-steady state situations. In such situations the values of the elastic moduli of the interface and of the exponent $\mathrm{n}$ are important.

For the elastic moduli of the interface it appears that the specific length of the interface is, in this case, connected to an average length of the part of the fibers involved in the bridge. This would lead to a value for the rigidity of the interface that is much lower than the usual one. The influence of $\mathrm{n}$ is also easy to understand. The lower the value of $\mathrm{n}$, the larger the area which is "significantly" damaged. In order to get an idea of the relative importance of these coefficients on propagation, the case of a D.C.B. specimen with an initial delaminated area of $25 \mathrm{~mm}$ was treated. Using the relation $\mathrm{d}=1$ for the definition of the crack, the most influential parameter is interface stiffness. But this influence is relatively small.

In fact, in the case of fiber-bridging, one problem is to define the value of the length of the crack. Experimentally, this value corresponds to the tip of the fiber-bridge. Consequently a part of the interface specimen ahead of the crack tip is contributing to its stiffness. A simple way to take this aspect into account is to define the crack tip using a value $d_{c}$ of the damage lower than 1 . In figure 7 a result obtained with this value fixed at .5 is presented. It appears that a large R-curve effect is obtained. This type of result may be encountered in experiments [15]. Of course the choice of $d_{c}$ should be carefully determined in each case.

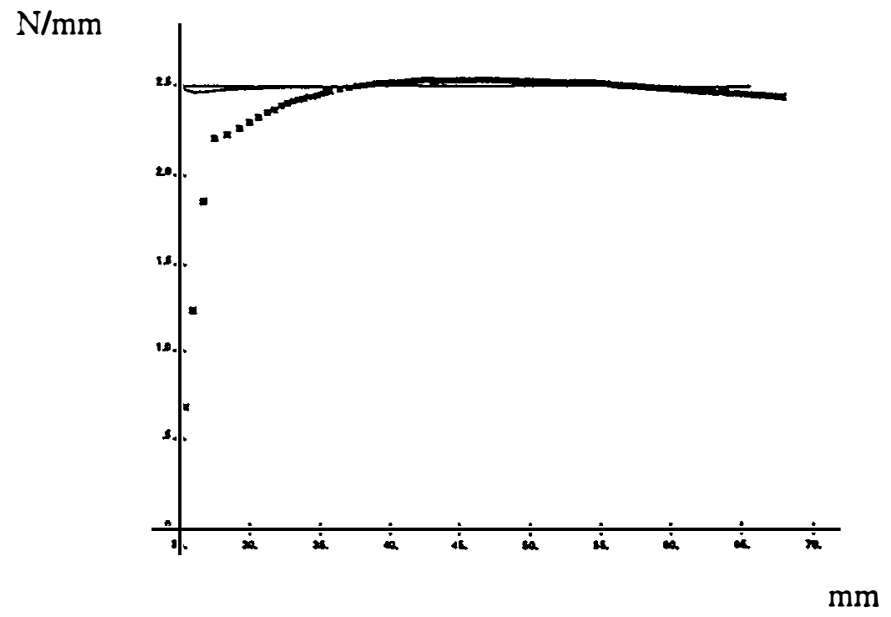

Figure 7. Values of the critical energy release rate in mode $I$ for a crack type defined by $\mathrm{d}=.5$. 


\section{INITIATION PREDICTION}

The study of the creation of a new delamination crack is often investigated by means of Edge Delamination Tension specimens [27]. In such a case Fracture Mechanics is not well adapted. The reason is that the energy release rate tends to zero with the size of the crack. Moreover, the analysis of stress singularities does not allow a simple comparison of the state of different interfaces. In fact the type and the exponent of the singularity depend on the interface. Thus, for the forecast of the onset of a edge delamination crack, computational methods of elastic edge effects [28-30], associated with criteria [16] are used. These criteria are often based upon the average of interlaminar stresses on a specific distance from the free edge. Nevertheless delamination does not always occur where stresses are maximal. Moreover the specific distance from the free edge does not seem to be an intrinsic parameter when geometry and stacking sequence vary.

In addition, delamination, especially at its onset, appears to result from an intricate interaction between inner layer damage mechanisms and the deterioration of the interlaminar interface itself [3-4]. In that case its seems adequate to use the previously defined mesomodeling for the layer and the interface. This was done in [11] for the prediction of initiation and propagation of delamination and damages around initially circular holes. In this type of situation, classical approaches are clearly insufficient, and damage mechanics appears today to be, perhaps, the only way to deal with such a problem.

In order to emphasise the interest of Damage Mechanics of Interface for the prediction of initiation, let us consider the case where damage phenomena are supposed to be located only on the interface. The delamination analysis is carried out as a post-processor of an elastic laminate shell computation. A specialised software (Edge Damage Analysis) was developed where the layers, modeled as elastic, are connected by damageable interlaminar interfaces [12],[31]. EDT specimens under tension and compression were simulated. In such cases the numerical problem is set in a strip perpendicular to the edge. This type of problem has been studied in a similar way in [32].

The simulations are compared with experimental results, in the case of a T300-5208 material [16-17] for mode I and mode I \&II delamination (Fig. 8 and 9 ).

In mode I cases, delamination occurs on the mid-plane interface. The values of the longitudinal strain at the onset of delamination are compared. The same value of $Y_{c}$ was used for the six cases which have been treated. Even they were nearly pure mode I cases, the state of stress is very different from one case to the other. It is thus surprising that only one parameter allowed for obtaining such a similarity ( a maximum relative error of about $10 \%$, figure 8). A tentative explanation is that, in each case, it is the same interface $[ \pm 09$ submitted to the same mode of loading which is prone to delamination. 


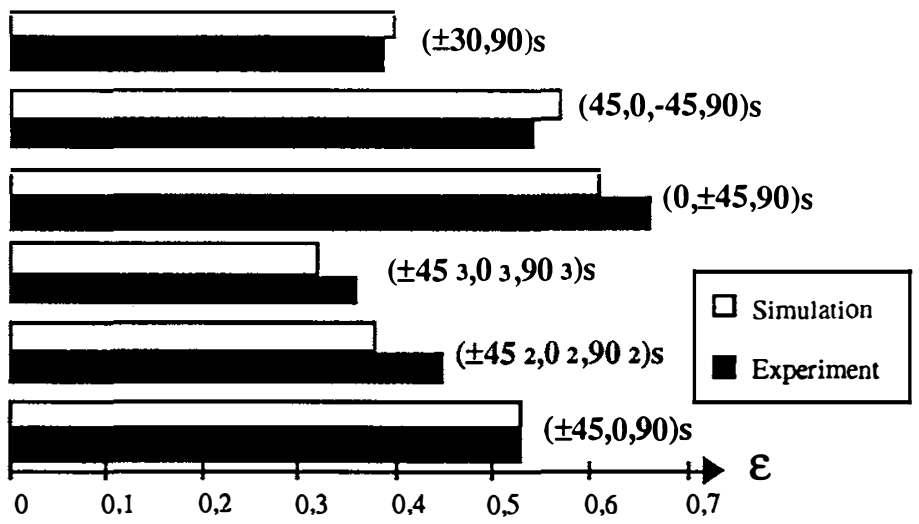

Figure 8. Longitudinal strain at onset of delamination (mode I)

In mixed mode cases the values of the coupling coefficient must also be specified. It was assumed that $\gamma_{1}=\gamma_{2}$ with an estimated value of .2. The comparison is still encouraging and the location of the onset of delamination was correctly predicted (Fig. 9). Nevertheless the results are less satisfactory than in pure mode I since an average relative error of $15 \%$ was obtained.

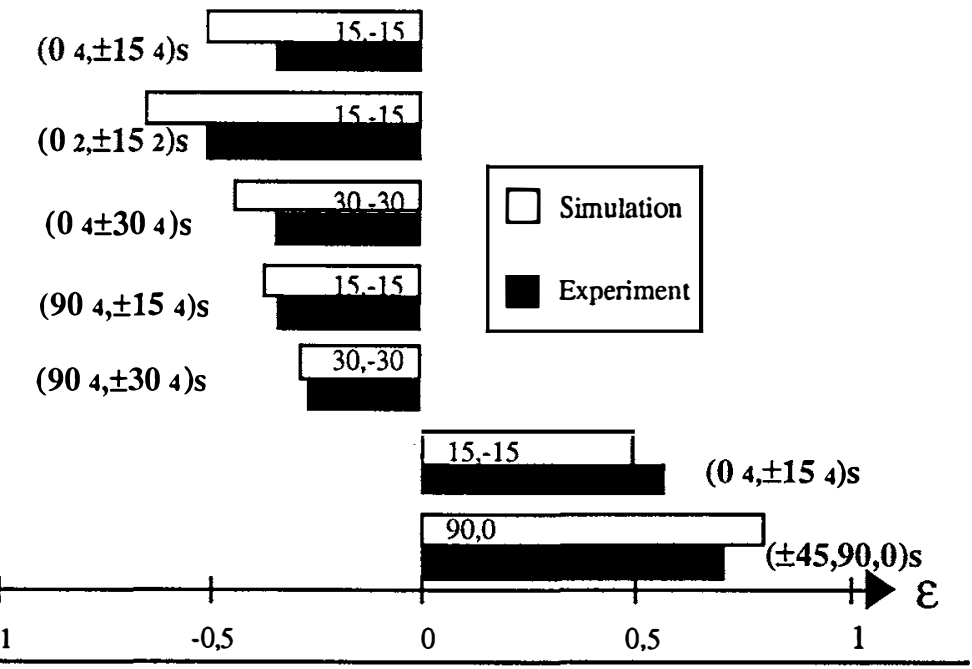

Figure 9. Longitudinal strain at initiation of delamination andidelaminated interface ( mixed mode)

A tentative explanation is that the same values of the material characteristics of the 
interface model was chosen for all the interfaces. In fact, for these last comparisons, the interfaces which are prone to delamination are different: $[ \pm 15],[ \pm 30],[ \pm 45]$. Thus different characteristics could have been chosen depending on the type of interface.

6. IMPLEMENTATION OF THE MESO-MODELING FOR STRUCTURAL ANALYSES

A code, devoted to high gradient areas of laminated structures, is under development [33]. It extends a code dedicated to the delamination analysis of laminate structures with an initiallycircular hole [11], [34]. It is a Finite Element Code which includes the previous damage mesomodel. Thus, two types of constituents are discretized: the elementary layer and the interface. An example of a holed plate $\left[+22.5^{\circ},-22.5^{\circ}\right]_{s}$ submitted to tension is presented below (figures 10).

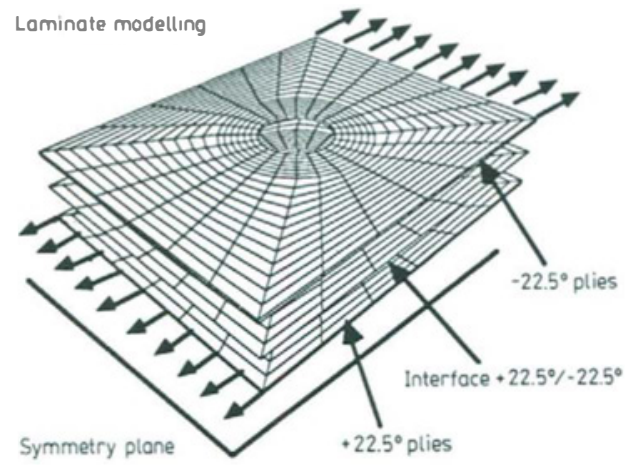

Figure 10. A structural computation example

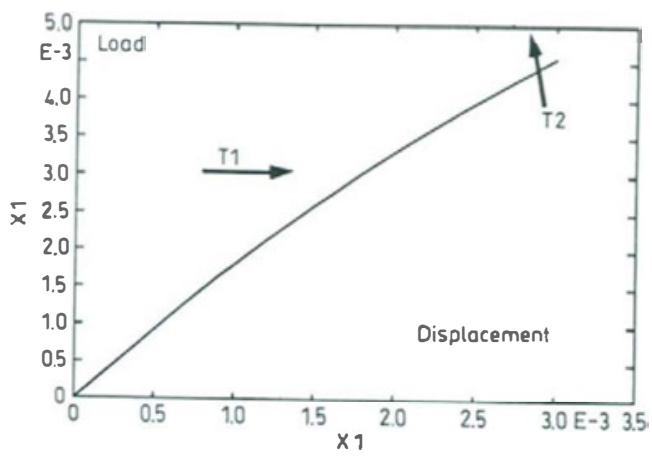

Figure 11. Load history
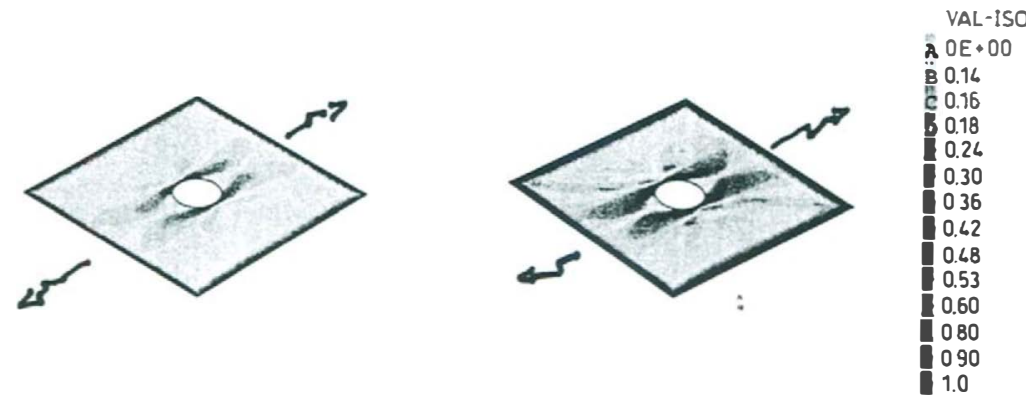

Figure 12. Damage variable $d$ of the interface at times $T_{1}$ and $T_{2}$ 

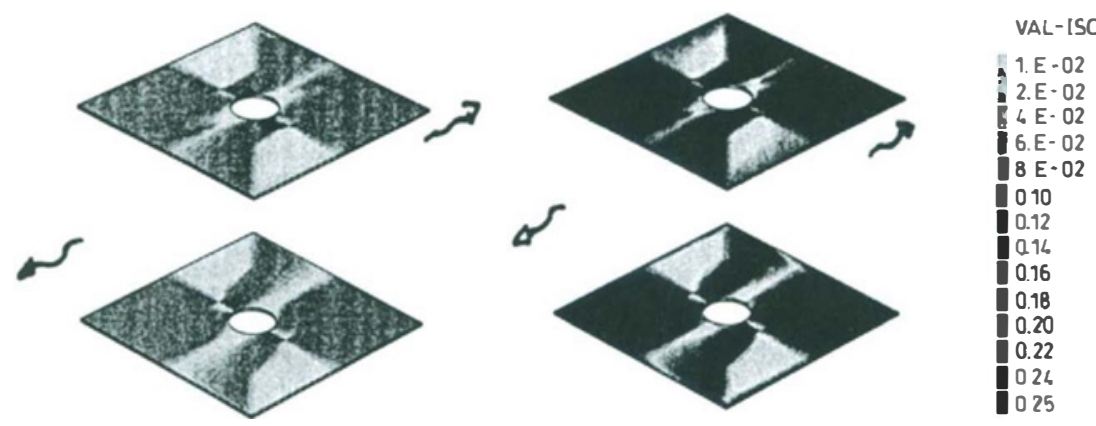

Figure 13. Transverse cracking indicators at times $T_{1}$ and $T_{2}$

The load history is shown in figure 10. At any point and at any time, the code gives the level of the different damage mechanisms up until the ultimate fracture. The main damage mechanism herein is delamination, i.e. the deterioration of the interface $\left[22.5^{\circ},-22.5^{\circ}\right]$ (Fig. 11). Figure 12. gives the value of the damage variable $d$ at times $T_{1}$ and $T_{2}$. The increase of the delaminated area is quite large. The layer damage mechanisms are weakly excited (Figure 13.).

\section{CONCLUSION}

A Meso-Damage modeling of laminates whose aim is to determine the properties of any structures with regards to delamination, by knowing only a few characteristics of the interface has been detailed. Examples show that this approach is promising for the prediction of delamination in various circumstances [11-13]. Nevertheless, one of the first challenges will be to build a good interface model, i. e. a model which allows for predicting, using a single set of parameters, both the creation and the propagation of a delamination crack on a large range.

Difficulties are also encountered when trying to get a complete identification of the interlaminar interfacial model. The goal will be then to define canonical tests which allow' a complete and precise identification of the interlaminar interface model. Progress can be made by comparing experiments and tests in the case of the creation and beginning of propagation of a new delamination crack.

We also want to insist on the necessity of including more physics in the modeling of the interface. In fact, a more precise description of the interlaminar connection with respect to its constitution and geometrical characteristics could lead to a more precise link between meso and micro-parameters. 


\section{REFERENCES}

1. A. Highsmith, and K.L.Reifsnider, Stiffness reduction mechanism in composite material, In: ASTM-STP 775, Damage in Composite Materials, AS.T.M., pp.103117., 1982

2. R. Talreja, Transverse cracking and stiffness reduction in composite laminates, Journal of Composite Materials, vol.19, pp. 355-375, 1985

3. C. A Garg, Delamination. A damage mode in composite structures. Engineering Fracture Mechanics, Vol 29, n5, pp. 557-584, 1988.

4. Whithney, J.M. Experimental characterization of delamination fracture. In: Interlaminar response of composite materials, Comp.Mat. Series, 5, Pagano, N. J. ed, 111-239, 1989

5. P. Ladevèze, Sur la Mécanique de l'Endommagement des composites. In: Comptes rendus des JNC 5, C. Bathias \& D. Menkès eds, Pluralis Publication, Paris, pp. 667683, 1986

6. P. Ladevèze, Towards a Fracture Theory, Proceedings of the third International Conference on computational Plasticity Part II, D.R.J. Owen, E. Onate, E. Hinton ed, Pineridge press, Cambridge U.K., 1992, pp. 1369-1400

7. P. Ladevèze, O. Allix and L. Daudeville, Mesomodeling of Damage for Laminate Composites. Application to Delamination. In: Inelastic Deformation of Composites Materials,.Springer -Verlag, Dvorak, V.D. ed, pp. 607-622, 1990.

8. P. Ladevèze, A damage computational method for composite structures, J. Computer and Structure, 44 (1/2), pp. 79-87, 1992

9. O. Allix, O. and P. Ladevèze, A meso-modelling approach for delamination prediction. In: Fracture and Damage in Quasibrittle Structures. Bazant, Z. P., Bittnar, Z., Jirasek, M. eds, pp. 606-15, 1994

10. P. Ladevèze and E. Le Dantec, Damage modeling of the elementary ply for laminated composites, Composite Science and Technology, 43-3, pp.257-267, 1992

11. O. Allix, O. and P. Ladevèze, Interlaminar interface modelling for the prediction of laminates delamination., Composite Sructures 22, pp. 235-242., 1992

12. Daudeville L. and P. Ladevèze, A Damage Mechanics Tool for Laminate Delamination", Journal of Composite Structures $n^{\circ} 25,1993$, pp. 547-555.

13. O. Allix, A. Corigliano and P. Ladevèze, Damage analysis of interlaminar Fracture specimens, Composite Sructures. 31, 1995, pp. 61-74.

14. O. Allix, L. Daudeville, J.L. Neau, and P. Ladevèze, Necessity of using Damage Mechanics for the analysis of delamination specimens, COMPLAS IV: 4th Int. Conf. on Comp. Plas. Fund. and App., Barcelona, 1995, pp 1057-1068. 
15. S. Hashemi, A J. Kinloch and J. G. Williams, Mechanics and Mechanisms of Delamination in a Poly(ether sulphone)-Fibre Composite. Composite Science and Technology, 37, pp. 429-462, Elsevier Science Publishers, 1990

16. R.Y. Kim and S. R. Soni, Experimental and Analytical Studies on the Onset of Delamination in Laminated Composites, Journal of Composite Materials, 18 Oplinger \& Burke (Ed.), pp. 70-76, 1984

17. R.Y. Kim and S. R. Soni, Delamination of Composite Laminates Stimulated by Interlaminar Shear. In: ASTM-STP 893, 286-307, 1986

18. A Laksimi, M L. Benzeggagh, G. Jing, M Hecini and J. M. Roelandt, Mode I Interlaminar Fracture of Symmetrical Cross-ply Composites. Composites Science and Technology, 41, Elsevier Science Publishers, pp. 147-164, 1991

19. Z. P. Bazant, Z. Bittnar and M. Jirasek (eds), Fracture and Damage in Quasibrittle Structures, 1994

20. J.L. Billoet, T. Ben Zineb and B. Ben Lazreg, Approche semi-mésoscopique et effets de bords libres des plaques stratifiées, in Délaminage. Bilan et perspectives, Journées AMAC/CSMA, Annales des composites 95/1, O. Allix \&M.L Benzeggagh eds, Amac Publication, pp. 129-138, 1995

21. O. Allix and A. Corigliano, Modeling and simulation of crack propagation in mixedmodes interlaminar fracture specimens. Submitted for publication to Int. J. of Fracture

22. G.R. Irwin and J.A. Kies, Critical energy rate analysis of fracture strength. Welding Research, Supplement, Vol 19, pp. 193-198, 1954

23. A.Hilledeborg, M. Modeer and P.E. Peterson, Analysis of crack Formation and crack growth in concrete by means of Fracture Mechanics and Finite elements. Cement and Concrete research, 6, 773-782, 1976.

24. D. S. Dugdale, Yielding of steel sheets containing slits. J. Mech. Phys. Solids, 8, 1004, 1960.

25. Z. Suo, G. Bao and B. Fan, Delamination R-curve phenomena due to damage, International Journal of Mec. Phy. Sol., pp. 1-15, 1992

26. L. Daridon, B. Cochelin and M. Potier-Ferry, Modélisation d'un délaminage avec pont de fibres dans différentes éprouvettes composites. In: Comptes-rendus des neuvièmes Journées nationales sur les composites, J.P. Favre \& A. Vautrin eds, AMAC publication, pp. 393-402, 1994

27. T. K. O'Brien, Characterisation of Delamination Onset and Growth in a Composite Laminate. In: Damage in Composite Materials, Reifsnider K.L. ed., ASTM-STP 775, 140-167, 1982

28. P. Bar-Yoseph, On the Accuracy of Interlaminar Stress Calculation in Laminated Plates. Comp. Meth. in Applied Mech. and Eng., 36 309-329, 1983 
29. H. Dumontet, Study of a Boundary Layer Problem in Elastic Composite Materials. $M^{2}$ AN, 20, 265-286, 1986

30. D. Engrand, A Boundary Layer Approach to the Calculation of Transverse Stresses along the Free Edges of a Symmetric Laminated Plate of Arbitrary Width under in Plane Loading. Composite Structures, 247-261, 1981

31. Daudeville L. and P. Ladevèze, Une méthode simplifiée pour l'étude du délaminage auprès d'un bord droit, Revue Européenne des Eléments Finis, Vol 3, 1994, pp. 127-150.

32. J. C. Schellekens and R. De Borst, A non-linear finite element approach for the analysis of mode I-free edge delamination in composites, Int. Journal Solids Structures vol. 309, 1239-53, 1993.

33. L. Gornet, Simulation des endommagements et de la rupture dans les composites stratifiés, Thesis to appear

34. O. Allix, Délaminage. Approche par la mécanique de l'endommagement. In: Calcul des Structures et Intelligence Artificielle, Vol 1, Fouet, J.M., Ladevèze, P., Ohayon, R., Eds., Pluralis, pp. 39-53, 1987. 